\title{
How to identify and treat common bites and stings
}

\section{A thorough history and physical are key to proper diagnosis and treatment following a patient's encounter with an insect, arachnid, or other arthropod.}

\section{PRACTICE RECOMMENDATIONS \\ > Recommend that patients \\ I} use an insect repellent, such as an over-the-counter formulation that contains DEET, picaridin, or PMD (a chemical constituent of Eucalyptus citriodora oil) to prevent flea bites. (C)

> Prescribe nonsedating oral antihistamines as first-line symptomatic treatment of mild-to-moderate pruritus secondary to an insect bite. (C)

> When indicated, refer patients for venom immunotherapy, which is approximately 95\% effective in preventing or reducing severe systemic reactions and reduces the risk of anaphylaxis and death. (A)

Strength of recommendation (SOR)

(A) Good-quality patient-oriented evidence

B Inconsistent or limited-quality patient-oriented evidence

C Consensus, usual practice, opinion, disease-oriented evidence, case series nsect, arachnid, and other arthropod bites and stings are common patient complaints in a primary care office. A thorough history and physical exam can often isolate the specific offender and guide management. In this article, we outline how to identify, diagnose, and treat common bites and stings from bees and wasps; centipedes and spiders; fleas; flies and biting midges; mosquitoes; and ticks, and discuss how high-risk patients should be triaged and referred for additional testing and treatment, such as venom immunotherapy (VIT).

\section{Insects and arachnids:}

\section{Background and epidemiology}

I Insects are arthropods with 3-part exoskeletons: head, thorax, and abdomen. They have 6 jointed legs, compound eyes, and antennae. There are approximately 91,000 insect species in the United States, the most abundant orders being Coleoptera (beetles), Diptera (flies), and Hymenoptera (includes ants, bees, wasps, and sawflies). ${ }^{1}$

The reported incidence of insect bites and stings varies widely because most people experience mild symptoms and therefore do not seek medical care. Best statistics are for Hymenoptera stings, which are more likely to cause a severe reaction. In Europe, $56 \%$ to $94 \%$ of the general population has reported being bitten or stung by one of the Hymenoptera species. ${ }^{2}$ In many areas of Australia, the incidence of jack jumper ant stings is only $2 \%$ to $3 \%^{3}$; in the United States, $55 \%$ of people report being stung by nonnative fire ants within 3 weeks of moving into an endemic area. ${ }^{4}$

I Arachnids are some of the earliest terrestrial organisms, of the class Arachnida, which includes scorpions, ticks, spiders, mites, and daddy longlegs (harvestmen). ${ }^{5}$ Arachnids are wingless and characterized by segmented bodies, jointed appendages, and exoskeletons. ${ }^{6,7}$ In most, the body is separated into 2 segments (the cephalothorax and abdomen), except for

\section{Ecler Ercole Jaqua, MD, DipABLM, FAAFP; Mary Hanna, MD; Hobart Lee, MD, FAAFP \\ Department of Family Medicine, Loma Linda University Health, CA \\ Đ ejaqua@llu.edu}

The authors reported no potential conflict of interest relevant to this article.

doi: 10.12788/jfp.0111 


\section{FIGURE 1}

\section{Large local reaction}

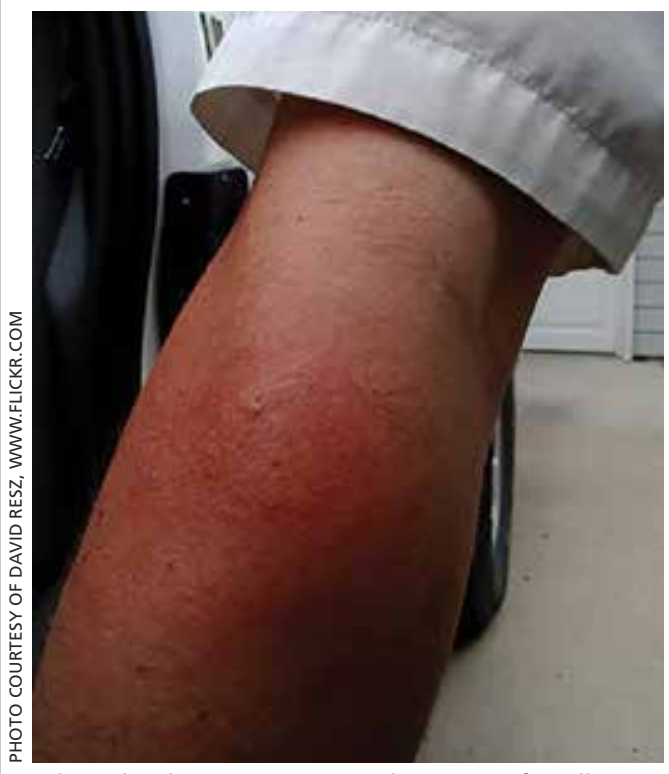

A large local reaction is one with an area of swelling $>10 \mathrm{~cm}$ in diameter that lasts $>24$ hours.

mites, ticks, and daddy longlegs, in which the entire body comprises a single segment. ${ }^{5}$

Arthropod bites are common in the United States; almost one-half are caused by spiders. ${ }^{7}$ Brown recluse (Loxosceles spp) and black widow (Latrodectus spp) spider bites are the most concerning: Although usually mild, these bites can be life-threatening but are rarely fatal. In 2013, almost 3500 bites by black widow and brown recluse spiders were reported. ${ }^{8}$

\section{Risk factors}

Risk factors for insect, arachnid, and other arthropod bites and stings are primarily environmental. People who live or work in proximity of biting or stinging insects (eg, gardeners and beekeepers) are more likely to be affected; so are those who work with animals or live next to standing water or grassy or wooded locales.

There are also risk factors for a systemic sting reaction:

- A sting reaction $<2$ months earlier increases the risk of a subsequent systemic sting reaction by $\geq 50 \%{ }^{9}$

- Among beekeepers, paradoxically, the risk of a systemic reaction is higher in those stung $<15$ times a year than in those stung $>200$ times. $^{10}$

- Patients with an elevated baseline serum level of tryptase (reference range, $<11.4 \mathrm{ng} / \mathrm{mL}$ ), which is part of the allergenic response, or with biopsyproven systemic mastocytosis are at increased risk of a systemic sting reaction. $^{11}$

\section{Presentation: Signs and symptoms vary with severity}

Insect bites and stings usually cause transient local inflammation and, occasionally, a toxic reaction. Allergic hypersensitivity can result in a large local reaction or a generalized systemic reaction ${ }^{12}$ :

- A small local reaction is transient and mild, develops directly at the site of the sting, and can last several days. ${ }^{13}$

- A large (or significant) local reaction, defined as swelling $>10 \mathrm{~cm}$ in diameter (FIGURE 1) and lasting $>24$ hours, occurs in $2 \%$ to $26 \%$ of people who have been bitten or stung. ${ }^{14}$ This is an immunoglobulin (Ig) E-mediated latephase reaction that can be accompanied by fatigue and nausea. ${ }^{12,13,15}$ For a patient with a large local reaction, the risk of a concomitant systemic reaction is $4 \%$ to $10 \%$, typically beginning within 30 minutes after envenomation or, possibly, delayed for several hours or marked by a biphasic interval. ${ }^{16}$

- Characteristics of a systemic reaction are urticaria, angioedema, bronchospasm, large-airway edema, hypotension, and other clinical manifestations of anaphylaxis. ${ }^{17}$ In the United States, a systemic sting reaction is reported to occur in approximately $3 \%$ of bite and sting victims. Mortality among the general population from a systemic bite or sting reaction is 0.16 for every 100,000 people, $^{2}$ and at least 40 to 100 die every year in the United States from anaphylaxis resulting from an insect bite or sting. ${ }^{18}$

- The most severe anaphylactic reactions involve the cardiovascular and respiratory systems, commonly including hypotension and symptoms 
of upper- or lower-airway obstruction. Laryngeal edema and circulatory failure are the most common mechanisms of anaphylactic death. ${ }^{19}$

\section{Bees and wasps}

Hymenoptera stinging insects include the family Apidae (honey bee, bumblebee, and sweat bee) and Vespidae (yellow jacket, yellow- and white-faced hornets, and paper wasp). A worker honey bee can sting only once, leaving its barbed stinger in the skin; a wasp, hornet, and yellow jacket can sting multiple times (FIGURE 2). ${ }^{20}$

Bee and wasp sting allergies are the most common insect venom allergic reactions. A bee sting is more likely to lead to a severe allergic reaction than a wasp sting. Allergic reactions to hornet and bumblebee stings are less common but can occur in patients already sensitized to wasp and honey bee stings. ${ }^{20,21}$

I Management. Remove honey bee stingers by scraping the skin with a fingernail or credit card. Ideally, the stinger should be removed in the first 30 seconds, before the venom sac empties. Otherwise, intense local inflammation, with possible lymphangitic streaking, can result. ${ }^{22}$

For guidance on localized symptomatic care of bee and wasp stings and bites and stings from other sources discussed in this article, see "Providing relief and advanced care" on page E6.

\section{Centipedes and spiders}

I Centipedes are arthropods of the class Chilopoda, subphylum Myriapoda, that are characterized by repeating linear (metameric) segments, each containing 1 pair of legs. ${ }^{23}$ Centipedes have a pair of poison claws behind the head that are used to paralyze prey-usually, small insects. ${ }^{23,24}$ The bite of a larger centipede can cause a painful reaction that generally subsides after a few hours but can last several days. Centipede bites are usually nonfatal to humans. ${ }^{23}$

I Spiders belong to the class Arachnida, order Araneae. They have 8 legs with chelicerae (mouthpiece, or "jaws") that inject venom

\section{FIGURE 2}

\section{Wasp sting}

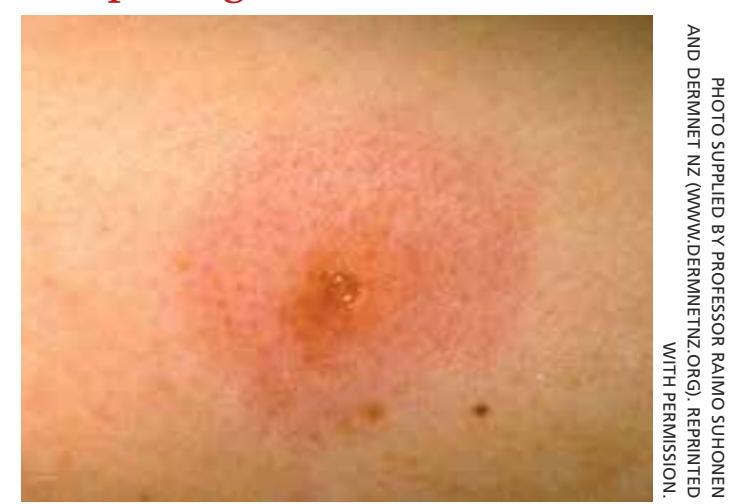

Unlike a bee, a wasp does not deposit its stinger in the skin.

\section{FIGURE 3}

\section{Brown recluse spider bite}

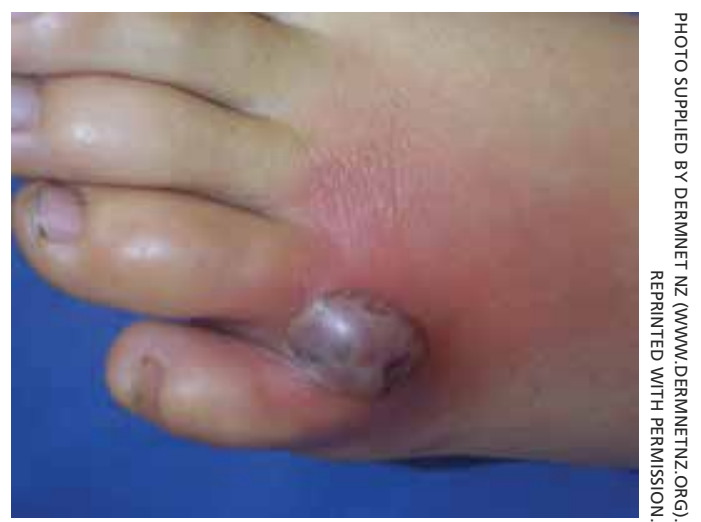

Here, a necrotic ulcer has developed at the site, subsequent to an erythematous halo.

into prey. ${ }^{25}$ Most spiders found in the United States cannot bite through human skin. ${ }^{26,27}$ Common exceptions are black widow and brown recluse spiders, which each produce a distinct toxic venom that can cause significant morbidity in humans through a bite, although bites are rarely fatal. ${ }^{26,27}$

The brown recluse spider is described as having a violin-shaped marking on the abdomen; the body is yellowish, tan, or dark brown. A bite can produce tiny fang marks and cause dull pain at the site of the bite that spreads quickly; myalgia; and pain in the stomach, back, chest, and legs. ${ }^{28,29}$ The bite takes approximately 7 days to resolve. In a minority of cases, a tender erythematous halo develops, followed by a severe necrotic 


\section{FIGURE 4}

\section{Flea bites}

Bites produce a small, erythematous papule with halo.

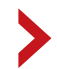

\section{A bee sting is more likely to lead to a severe allergic reaction than a wasp sting.}

ulcer, or loxoscelism (FIGURE 3; 40\% of cases) or scarring (13\%), or both..$^{29,30}$

In contrast, the body of a black widow spider is black; females exhibit a distinctive red or yellow hourglass marking on their ventral aspect. ${ }^{28,31}$ The pinprick sensation of a bite leads to symptoms that can include erythema, swelling, pain, stiffness, chills, fever, nausea, and stomach pain..$^{30,32}$

I Management. Again, see "Providing relief and advanced care" on page E6. Consider providing antivenin treatment for moderate or severe bites of brown recluse and black widow spiders.

\section{Fleas}

Fleas are members of the order Siphonaptera. They are small (1.5-3.2 $\mathrm{mm}$ long), reddish brown, wingless, blood-sucking insects with long legs that allow them to jump far (12 or 13 inches) and high (6 or 7 inches) ${ }^{33}$ Domesticated cats and dogs are the source of most flea infestations, resulting in an increased risk of exposure for humans. ${ }^{34,35}$ Flea bites, which generally occur on lower extremities, develop into a small, erythematous papule with a halo (FIGURE 4) and associated mild edema, and cause intense pruritus 30 minutes after the bite. $^{35-37}$

Fleas are a vector for severe microbial infections, including bartonellosis, bubonic plague, cat-flea typhus, murine typhus, cat-scratch disease, rickettsial disease, and tularemia. Tungiasis is an inflammatory bur- rowing flea infestation-not a secondary infection for which the flea is a vector. ${ }^{34,35}$

I Preventive management. Repellents, including products that contain DEET (N,N-diethyl-meta-toluamide), picaridin (2-[2-hydroxyethyl]-1-piperidinecarboxylic acid 1-methylpropyl ester), and PMD (p-menthane-3,8-diol, a chemical constituent of Eucalyptus citriodora oil) can be used to prevent flea bites in humans. ${ }^{33,38}$ Studies show that the scent of other botanic oils, including lavender, cedarwood, and peppermint, can also help prevent infestation by fleas; however, these compounds are not as effective as traditional insect repellents. ${ }^{33,38}$

Flea control is difficult, requiring a multimodal approach to treating the infested animal and its environment. ${ }^{39}$ Treatment of the infested domestic animal is the primary method of preventing human bites. Nonpesticidal control involves frequent cleaning of carpeting, furniture, animal bedding, and kennels. Insecticides can be applied throughout the house to combat severe infestation. ${ }^{33,38}$

The Centers for Disease Control and Prevention provide a general introduction to getting rid of fleas for pet owners. ${ }^{40}$ For specific guidance on flea-eradication strategies and specific flea-control products, advise patients to seek the advice of their veterinarian.

\section{Flies and biting midges}

I Flies are 2-winged insects belonging to the order Diptera. Several fly species can bite, causing a local inflammatory reaction; these include black flies, deer flies, horse flies, and sand flies. Signs and symptoms of a fly bite include pain, pruritus, erythema, and mild swelling (FIGURE 5). ${ }^{41,42}$ Flies can transmit several infections, including bartonellosis, enteric bacterial disease (eg, caused by Campylobacter spp), leishmaniasis, loiasis, onchocerciasis, and trypanosomiasis. ${ }^{43}$

I Biting midges, also called "no-seeums," biting gnats, moose flies, and "punkies," ${ }^{44}$ are tiny (1-3 mm long) blood-sucking flies ${ }^{45}$ Bitten patients often report not having seen the midge because it is so small. The bite typically starts as a small, erythematous papule that develops into a dome-shaped blister 
and can be extraordinarily pruritic and painful. ${ }^{44}$ The majority of people who have been bitten develop a hypersensitivity reaction, which usually resolves in a few weeks.

I Management. Suppressing adult biting midges with an environmental insecticide is typically insufficient because the insecticide must be sprayed daily to eradicate active midges and generally does not affect larval habitat. Insect repellents and biopesticides, such as oil of lemon eucalyptus, can be effective in reducing the risk of bites. ${ }^{44,45}$

\section{Mosquitoes}

Mosquitoes are flying, blood-sucking insects of the order Diptera and family Culicidae. Anopheles, Culex, and Aedes genera are responsible for most bites of humans.

The bite of a mosquito produces an indurated, limited local reaction characterized by a pruritic wheal (3-29 $\mathrm{mm}$ in diameter) with surrounding erythema (FIGURE 6) that peaks in approximately 30 minutes, although patients might have a delayed reaction hours later. ${ }^{46}$ Immunocompromised patients might experience a more significant local inflammatory reaction that is accompanied by lowgrade fever, hives, or swollen lymph nodes. ${ }^{46,47}$

Mosquitoes are a vector for serious infections, including dengue, Japanese encephalitis, malaria, and yellow fever, and disease caused by Chikungunya, West Nile, and Zika viruses.

I Management. Advise patients to reduce their risk by using insect repellent, sleeping under mosquito netting, and wearing a long-sleeve shirt and long pants when traveling to endemic areas or when a local outbreak occurs. ${ }^{48}$

\section{Ticks}

Ticks belong to the order Parasitiformes and families Ixodidae and Argasidae. Hard ticks are found in brushy fields and tall grasses and can bite and feed on humans for days. Soft ticks are generally found around animal nests. ${ }^{29}$ Tick bites can cause a local reaction that includes painful, erythematous, inflammatory papular lesions (FIGURE 7). ${ }^{49}$

Ticks can transmit several infectious dis-

FIGURE 5

\section{Multiple fly bites}

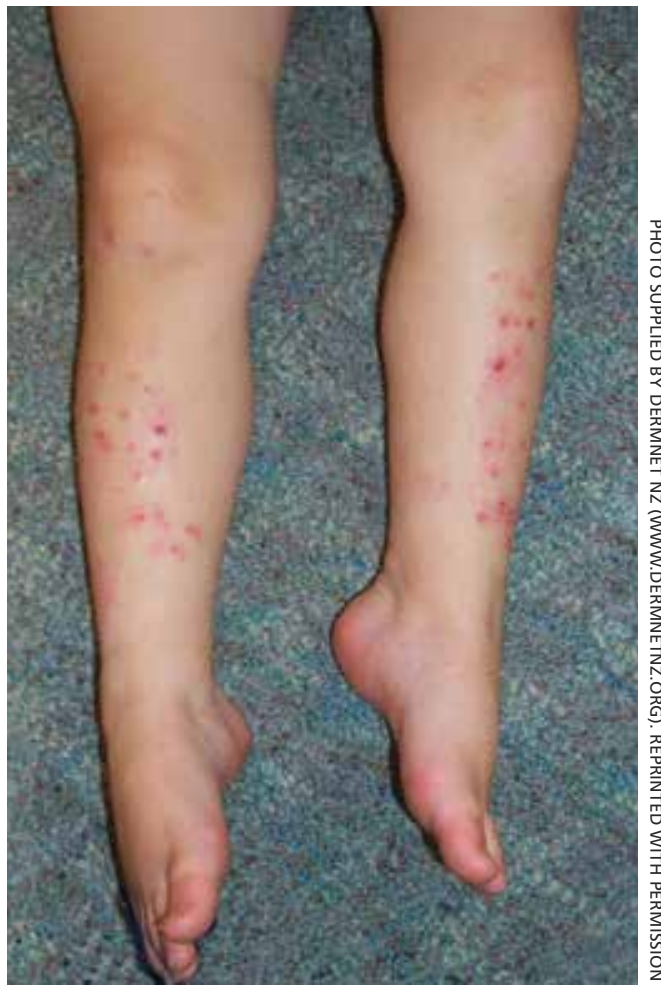

Bites exhibit erythema and mild swelling.

FIGURE 6

Mosquito bite

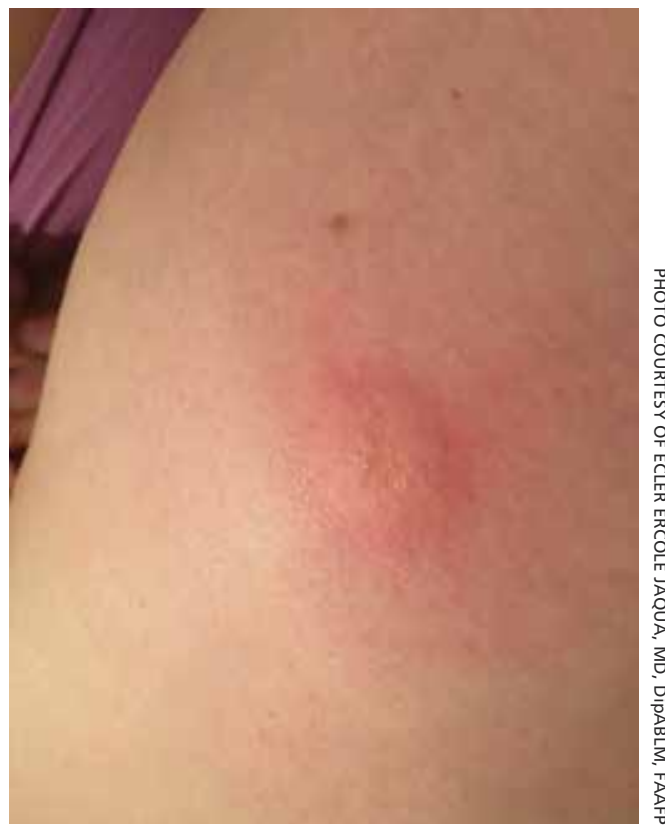

Induration, a pruritic wheal, and surrounding erythema characterize a local reaction.
Most spiders found in the United States can't bite through human skin. Common exceptions are black widow and brown recluse spiders. 


\section{FIGURE 7}

\section{Tick bite}

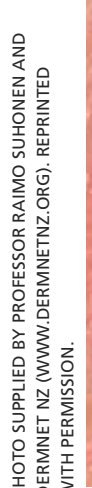

Embedding can provoke a painful, erythematous, papular lesion.

eases. Depending on the microbial pathogen and the genus and species of tick, it takes 2 to 96 hours for the tick to attach to skin and transmit the pathogen to the human host. The TABLE ${ }^{29,49,50}$ provides an overview of tick species in the United States, diseases that they can transmit, and the geographic distribution of those diseases.

I Management. Ticks should be removed with fine-tipped tweezers. Grasp the body of the tick close to the skin and pull upward while applying steady, even pressure. After removing the tick, clean the bite and the surrounding area with alcohol or with soap and water. Dispose of a live tick by flushing it down the toilet; or, kill it in alcohol and either seal it in a bag with tape or place it in a container. ${ }^{50}$

\section{Diagnosis and the utility of special testing}

The diagnosis of insect, arachnid, and other arthropod bites and stings depends on the history, including obtaining a record of possible exposure and a travel history; the timing of the bite or sting; and associated signs and symptoms. ${ }^{18,51}$

I Venom skin testing. For Hymenoptera stings, intradermal tests using a venom concentration of 0.001 to $1 \mu \mathrm{g} / \mathrm{mL}$ are positive in $65 \%$ to $80 \%$ of patients with a history of a systemic insect-sting allergic reaction. A negative venom skin test can occur during the 3-to-6-week refractory period after a sting re- action or many years later, which represents a loss of sensitivity. Positive venom skin tests are used to confirm allergy and identify specific insects to which the patient is allergic. . $^{11,12}$

I Allergen-specific IgE antibody testing. These serum assays-typically, radioallergosorbent testing (RAST)-are less sensitive than venom skin tests. RAST is useful when venom skin testing cannot be performed or when skin testing is negative in a patient who has had a severe allergic reaction to an insect bite or sting. Serum IgE-specific antibody testing is preferred over venom skin testing in patients who are at high risk of anaphylaxis. ${ }^{52,53}$

\section{Providing relief} and advanced care

I Symptomatic treatment of mild bites and stings includes washing the affected area with soap and water and applying a cold compress to reduce swelling. ${ }^{54}$ For painful lesions, an oral analgesic can be prescribed.

For mild or moderate pruritus, a lowto midpotency topical corticosteroid (eg, hydrocortisone valerate cream $0.2 \%$ bid), topical calamine, or pramoxine can be applied, or a nonsedating oral antihistamine, such as loratadine $(10 \mathrm{mg} / \mathrm{d})$ or cetirizine $(10 \mathrm{mg} / \mathrm{d})$, can be used..$^{14,55}$ For severe itching, a sedating antihistamine, such as hydroxyzine (10-25 mg every 4 to 6 hours prn), might help relieve symptoms; $\mathrm{H}_{1}$ - and $\mathrm{H}_{2}$-receptor antagonists can be used concomitantly. ${ }^{54,55}$

I Significant local symptoms. Large local reactions are treated with a midpotency topical corticosteroid (eg, triamcinolone acetonide cream $0.1 \%$ bid) plus an oral antihistamine to relieve pruritus and reduce allergic inflammation. For a more severe reaction, an oral corticosteroid (prednisone $1 \mathrm{mg} / \mathrm{kg}$; maximum dosage, $50 \mathrm{mg} / \mathrm{d}$ ) can be given for 5 to 7 days. ${ }^{54-56}$

Management of a necrotic ulcer secondary to a brown recluse spider bite is symptomatic and supportive. The size of these wounds can increase for as long as 10 days after the bite; resolution can require months of wound care, possibly with debridement. Rarely, skin grafting is required. ${ }^{27,28,31}$

I VIT. Some studies show that VIT can improve quality of life in patients with prolonged, frequent, and worsening reactions to 
TABLE

\section{Ticks and tick-borne diseases, and their US distribution ${ }^{29,49,50}$}

\begin{tabular}{|c|c|c|}
\hline $\begin{array}{l}\text { Vector (genus and } \\
\text { species) }\end{array}$ & Transmitted disease & Distribution \\
\hline \multicolumn{3}{|l|}{ Amblyomma } \\
\hline \multirow{2}{*}{ A americanum } & Erlichiosis, southern tick-associated rash illness & South and East \\
\hline & Tularemia & Nationwide \\
\hline A maculatum & Rickettsia parkeri rickettsiosis & Gulf Coast \\
\hline \multicolumn{3}{|l|}{ Dermacentor } \\
\hline$D$ andersoni & Colorado tick fever & Rocky Mountain states \\
\hline D andersoni & Rocky Mountain spotted fever, tularemia & Nationwide \\
\hline D occidentalis & Pacific Coast tick fever (Rickettsia philippi, strain 364D) & Pacific Coast \\
\hline$D$ variabilis & Rocky Mountain spotted fever, tularemia & Nationwide \\
\hline \multicolumn{3}{|l|}{ Ixodes } \\
\hline I cookei & Powassan disease & Northeast \\
\hline I pacificus & Anaplasmosis, Lyme disease & Pacific Coast \\
\hline \multirow{3}{*}{ I scapularis } & Anaplasmosis & Northeast, Upper Midwest \\
\hline & Babesiosis (Babesia microti), Powassan disease & Northeast \\
\hline & Lyme disease & Northeast, Upper Midwest, West \\
\hline \multicolumn{3}{|l|}{ Rhipicephalus } \\
\hline$R$ sanguineus & Rocky Mountain spotted fever & Nationwide \\
\hline
\end{tabular}

insect bites or stings and repeated, unavoidable exposures. ${ }^{55,56}$ VIT is recommended for patients with systemic hypersensitivity and a positive venom skin test result. It is approximately $95 \%$ effective in preventing or reducing severe systemic reactions and reduces the risk of anaphylaxis (see next section) and death. ${ }^{57}$ The maintenance dosage of VIT is usually $100 \mu$ g every 4 to 6 weeks; optimal duration of treatment is 3 to 5 years. ${ }^{58}$

After VIT is complete, counsel patients that a mild systemic reaction is still possible after an insect bite or sting. More prolonged, even lifetime, treatment should be considered for patients who have $\mathrm{e}^{58,59}$

- a history of severe, life-threatening allergic reactions to bites and stings

- honey bee sting allergy

- mast-cell disease

- a history of anaphylaxis while receiving VIT.
Absolute contraindications to VIT include a history of serious immune disease, chronic infection, or cancer. ${ }^{58,59}$

\section{Managing anaphylaxis}

This severe allergic reaction can lead to death if untreated. First-line therapy is intramuscular epinephrine, $0.01 \mathrm{mg} / \mathrm{kg}$ (maximum single dose, $0.5 \mathrm{mg}$ ) given every 5 to 15 minutes. ${ }^{14,60}$ Epinephrine auto-injectors deliver a fixed dose and are labeled according to weight. Administration of $\mathrm{O}_{2}$ and intravenous fluids is recommended for hemodynamically unstable patients. ${ }^{60,61}$ Antihistamines and corticosteroids can be used as secondary treatment but should not replace epinephrine. ${ }^{56}$

After preliminary improvement, patients might decompensate when the epinephrine dose wears off. Furthermore, a biphasic reaction, variously reported in $<5 \%$ to as many as $20 \%$ of patients, ${ }^{61,62}$ occurs hours after the ini- 
tial anaphylactic reaction. Patients should be monitored, therefore, for at least 6 to 8 hours after an anaphylactic reaction, preferably in a facility equipped to treat anaphylaxis. ${ }^{17,56}$

Before discharge, patients who have had an anaphylactic reaction should be given a prescription for epinephrine and training in the use of an epinephrine auto-injector. Allergen avoidance, along with an emergency plan in the event of a bite or sting, is recommended. Follow-up evaluation with an allergist or immunologist is essential for proper diagnosis and to determine whether the patient is a candidate for VIT. ${ }^{14,17}$

\section{CORRESPONDENCE}

Ecler Ercole Jaqua, MD, DipABLM, FAAFP, 1200 California Street, Suite 240, Redlands, CA 92374; ejaqua@llu.edu.

\section{The scent of botanic oils, including lavender and peppermint, can help prevent infestation by fleas.}

\section{References}

1. Numbers of insects (species and individuals). Smithsonian BugInfo Web site. www.si.edu/spotlight/buginfo/bugnos. Accessed November 25, 2020.

2. Antonicelli L, Bilò MB, Bonifazi F. Epidemiology of Hymenoptera allergy. Curr Opin Allergy Clin Immunol. 2002;2:341-346.

3. Jack jumper ant allergy. Australasian Society of Clinical Immunology and Allergy (ASCIA) Web site. Updated October 19, 2019. www.allergy.org.au/patients/insect-allergy-bites-and-stings/ jack-jumper-ant-allergy. Accessed November 25, 2020.

4. Kemp SF, deShazo RD, Moffit JE, et al. Expanding habitat of the imported fire ant (Solenopsis invicta): a public health concern. J Allergy Clin Immunol. 2000;105:683-691.

5. Goodnight ML. Arachnid. In: Encyclopaedia Britannica. 2012. www.britannica.com/animal/arachnid. Accessed November 25, 2020.

6. Despommier DD, Gwadz RW, Hotez PJ. Arachnids. In: Despommier DD, Gwadz RW, Hotez PJ. Parasitic Diseases. 3rd ed. Springer-Verlag; 1995:268-283.

7. Diaz JH, Leblanc KE. Common spider bites. Am Fam Physician. 2007;75:869-873

8. Mowry JB, Spyker DA, Cantilena LR Jr, McMillan N, Ford M. 2013 Annual report of the American Association of Poison Control Centers' National Poison Data System (NPDS): 31st Annual Report. Clin Toxicol (Phila). 2014;52:1032-1283.

9. Pucci $\mathrm{S}$, Antonicelli $\mathrm{L}$, Bilò $\mathrm{MB}$, et al Shortness of interval between two stings as risk factor for developing Hymenoptera venom allergy. Allergy. 1994;49:894-896.

10. Müller UR. Bee venom allergy in beekeepers and their family members. Curr Opin Allergy Clin Immunol. 2005;5:343-347.

11. Müller UR. Cardiovascular disease and anaphylaxis. Curr Opin Allergy Clin Immunol. 2007;7:337-341.

12. Golden DBK. Stinging insect allergy. Am Fam Physician. 2003;67:2541-2546.

13. Golden DBK, Demain T, Freeman T, et al. Stinging insect hypersensitivity: a practice parameter update 2016. Ann Allergy Asthma Immunol. 2017;118:28-54.

14. Bilò BM, Rueff F, Mosbech $\mathrm{H}$, et al; EAACI Interest Group on Insect Venom Hypersensitivity. Diagnosis of Hymenoptera venom allergy. Allergy. 2005;60:1339-1349.

15. Reisman RE. Insect stings. N Engl J Med. 1994;331:523-527.

16. Pucci S, D'Alò S, De Pasquale T, et al. Risk of anaphylaxis in patients with large local reactions to hymenoptera stings: a retrospective and prospective study. Clin Mol Allergy. 2015;13:21.

17. Golden DBK. Large local reactions to insect stings. J Allergy Clin Immunol Pract. 2015;3:331-334.

18. Clark S, Camargo CA Jr. Emergency treatment and prevention of insect-sting anaphylaxis. Curr Opin Allergy Clin Immunol.
2006;6:279-283.

19. Stinging insect allergy. In: Volcheck GW. Clinical Allergy: Diagnosis and Management. Humana Press; 2009:465-479.

20. Järvinen KM, Celestin J. Anaphylaxis avoidance and management: educating patients and their caregivers. J Asthma Allergy. 2014;7:95-104.

21. Institute for Quality and Efficiency in Health Care (IQWiG). Insect venom allergies: overview. InformedHealth.org. Updated May 7 2020. www.ncbi.nlm.nih.gov/pubmedhealth/PMH0096282/. Accessed November 25, 2020.

22. Casale TB, Burks AW. Clinical practice. Hymenoptera-sting hypersensitivity. N Engl J Med. 2014;370:1432-1439.

23. Shelley RM. Centipedes and millipedes with emphasis on North American fauna. Kansas School Naturalist. 1999;45:1-16. https:// sites.google.com/g.emporia.edu/ksn/ksn-home/vol-45-no3-centipedes-and-millipedes-with-emphasis-on-n-americafauna\#h.p_JEf3uDlTg0jw. Accessed November 25, 2020.

24. Ogg B. Centipedes and millipedes. Nebraska Extension in Lancaster County Web site. https://lancaster.unl.edu/pest/ resources/CentipedeMillipede012.shtml. Accessed November $25,2020$.

25. Cushing PE. Spiders (Arachnida: Araneae). In: Capinera JL, ed. Encyclopedia of Entomology. Springer, Dordrecht; 2008:226.

26. Diaz JH, Leblanc KE. Common spider bites. Am Fam Physician. 2007;75:869-873.

27. The National Institute for Occupational Safety and Health (NIOSH), Centers for Disease Control and Prevention. Venomous spiders. www.cdc.gov/niosh/topics/spiders/. Accessed November 25, 2020

28. Starr S. What you need to know to prevent a poisonous spider bite. AAP News. 2013;34:42. www.aappublications.org/content/ aapnews/34/9/42.5.full.pdf. Accessed November 25, 2020.

29. Spider bites. Mayo Clinic Web site. www.mayoclinic.org/ diseases-conditions/spider-bites/symptoms-causes/syc20352371. Accessed November 25, 2020.

30. Barish RA, Arnold T. Spider bites. In: Merck Manual (Professional Version). Merck Sharp \& Dohme Corp.; 2016. www. merckmanuals.com/professional/injuries-poisoning/bites-andstings/spider-bites. Accessed November 25, 2020.

31. Juckett G. Arthropod bites. Am Fam Physician. 2013;88:841-847.

32. Clark RF, Wethern-Kestner S, Vance MV, et al. Clinical presentation and treatment of black widow spider envenomation: a review of 163 cases. Ann Emerg Med. 1992;21:782-787.

33. Koehler PG, Pereira RM, Diclaro JW II. Fleas. Publication ENY025. University of Florida IFAS Extension. Revised January 2012. https://edis.ifas.ufl.edu/ig087. Accessed November 25, 2020.

34. Bitam I, Dittmar K, Parola P, et al. Fleas and flea-borne diseases. Int J Infect Dis. 2010;14:e667-e676.

35. Leulmi H, Socolovschi C, Laudisoit A, et al. Detection of Rickettsia felis, Rickettsia typhi, Bartonella species and Yersinia pestis in fleas (Siphonaptera) from Africa. PLoS Negl Trop Dis. 2014;8:e3152.

36. Naimer SA, Cohen AD, Mumcuoglu KY, et al. Household papular urticaria. Isr Med Assoc J. 2002;4(11 suppl):911-913.

37. Golomb MR, Golomb HS. What's eating you? Cat flea (Ctenocephalides felis). Cutis. 2010;85:10-11

38. Dryden MW. Flea and tick control in the 21st century: challenges and opportunities. Vet Dermatol. 2009;20:435-440.

39. Dryden MW. Fleas in dogs and cats. Merck Sharp \& Dohme Corporation: Merck Manual Veterinary Manual. Updated December 2014. www.merckvetmanual.com/integumentary-system/fleasand-flea-allergy-dermatitis/fleas-in-dogs-and-cats. Accessed November 25, 2020.

40. Centers for Disease Control and Prevention. Getting rid of fleas. www.cdc.gov/fleas/getting_rid.html. Accessed November 25, 2020.

41. Chattopadhyay P, Goyary D, Dhiman S, et al. Immunomodulating effects and hypersensitivity reactions caused by Northeast Indian black fly salivary gland extract. J Immunotoxicol. 2014;11:126-132.

42. Hrabak TM, Dice JP. Use of immunotherapy in the managemen of presumed anaphylaxis to the deer fly. Ann Allergy Asthma Immunol. 2003;90:351-354.

43. Royden A, Wedley A, Merga JY, et al. A role for flies (Diptera) in the transmission of Campylobacter to broilers? Epidemiol Infect. 2016;144:3326-3334.

44. Fradin MS, Day JF. Comparative efficacy of insect repellents against mosquito bites. N Engl J Med. 2002;347:13-18.

45. Carpenter S, Groschup MH, Garros C, et al. Culicoides biting 
midges, arboviruses and public health in Europe. Antiviral Res. 2013;100:102-113.

46. Peng Z, Yang M, Simons FE. Immunologic mechanisms in mosquito allergy: correlation of skin reactions with specific IgE and IgG anti-bodies and lymphocyte proliferation response to mosquito antigens. Ann Allergy Asthma Immunol. 1996;77:238-244.

47. Simons FE, Peng Z. Skeeter syndrome. J Allergy Clin Immunol. 1999;104:705-707.

48. Centers for Disease Control and Prevention. Travelers' health Clinician resources. wwwnc.cdc.gov/travel/page/clinicianinformation-center. Accessed November 25, 2020.

49. Gauci M, Loh RK, Stone BF, et al. Allergic reactions to the Australian paralysis tick, Ixodes holocyclus: diagnostic evaluation by skin test and radioimmunoassay. Clin Exp Allergy. 1989;19: 279-283.

50. Centers for Disease Control and Prevention. Ticks. Removing tick. www.cdc.gov/ticks/removing a tick.html. Accessed November 25, 2020.

51. Golden DB, Kagey-Sobotka A, Norman PS, et al. Insect sting allergy with negative venom skin test responses. J Allergy Clin Immunol. 2001;107:897-901.

52. Arzt L, Bokanovic D, Schrautzer C, et al. Immunological differences between insect venom-allergic patients with and withou immunotherapy and asymptomatically sensitized subjects. $A l-$ lergy. 2018;73:1223-1231.

53. Heddle R, Golden DBK. Allergy to insect stings and bites. World Allergy Organization Web site. Updated August 2015. www. worldallergy.org/education-and-programs/education/allergic- disease-resource-center/professionals/allergy-to-insect-stingsand-bites. Accessed November 25, 2020.

54. RuëffF, Przybilla B, Müller U, et al. The sting challenge test in Hymenoptera venom allergy. Position paper of the Subcommittee on Insect Venom Allergy of the European Academy of Allergology and Clinical Immunology. Allergy. 1996;51:216-225.

55. Management of simple insect bites: where's the evidence? Drug Ther Bull. 2012;50:45-48.

56. Tracy JM. Insect allergy. Mt Sinai J Med. 2011;78:773-783.

57. Golden DBK. Insect sting allergy and venom immunotherapy: a model and a mystery. J Allergy Clin Immunol. 2005;115:439-447.

58. Winther L, Arnved J, Malling H-J, et al. Side-effects of allergenspecific immunotherapy: a prospective multi-centre study. Clin Exp Allergy. 2006;36:254-260.

59. Mellerup MT, Hahn GW, Poulsen LK, et al. Safety of allergenspecific immunotherapy. Relation between dosage regimen, allergen extract, disease and systemic side-effects during induction treatment. Clin Exp Allergy. 2000;30:1423-1429.

60. Anaphylaxis and insect stings and bites. Med Lett Drugs Ther 2017;59:e79-e82.

61. Sampson HA, Muñoz-Furlong A, Campbell RL, et al. Second symposium on the definition and management of anaphylaxis: summary report-second National Institute of Allergy and Infectious Disease/Food Allergy and Anaphylaxis Network symposium. Ann Emerg Med. 2006;47:373-380.

62. Pflipsen MC, Vega Colon KM. Anaphylaxis: recognition and management. Am Fam Physician. 2020;102:355-362. Accessed November 25, 2020. 